Distance Learning, Parent-Child Interactions, and Affective Well-Being of Parents and Children During the COVID-19 Pandemic: A Daily Diary Study

Andrea Schmidt ${ }^{1,2}$, Andrea C. Kramer ${ }^{1,2}$, Annette Brose ${ }^{3}$, Florian Schmiedek ${ }^{1,2,4}$, \& Andreas B. Neubauer ${ }^{1,2}$

${ }^{1}$ DIPF | Leibniz Institute for Research and Information in Education, Frankfurt am Main, Germany

${ }^{2}$ Center for Research on Individual Development and Adaptive Education of Children at Risk (IDeA), Frankfurt am Main, Germany

${ }^{3}$ Humboldt University, Berlin, Germany

${ }^{4}$ Goethe-University, Frankfurt am Main, Germany

Correspondence concerning this article should be addressed to Andrea Schmidt, DIPF | Leibniz Institute for Research and Information in Education, and Center for Research on Individual Development and Adaptive Education of Children at Risk (IDeA), Rostocker Straße 6, 60323 Frankfurt a. M., Germany. E-mail: andrea.schmidt@dipf.de

We would like to thank Michaela Menstell for her valuable support in realizing the PACO project.

Data availability statement: The data that support the findings of this study are openly available in the OSF at: https://osf.io/ugkj2/. 


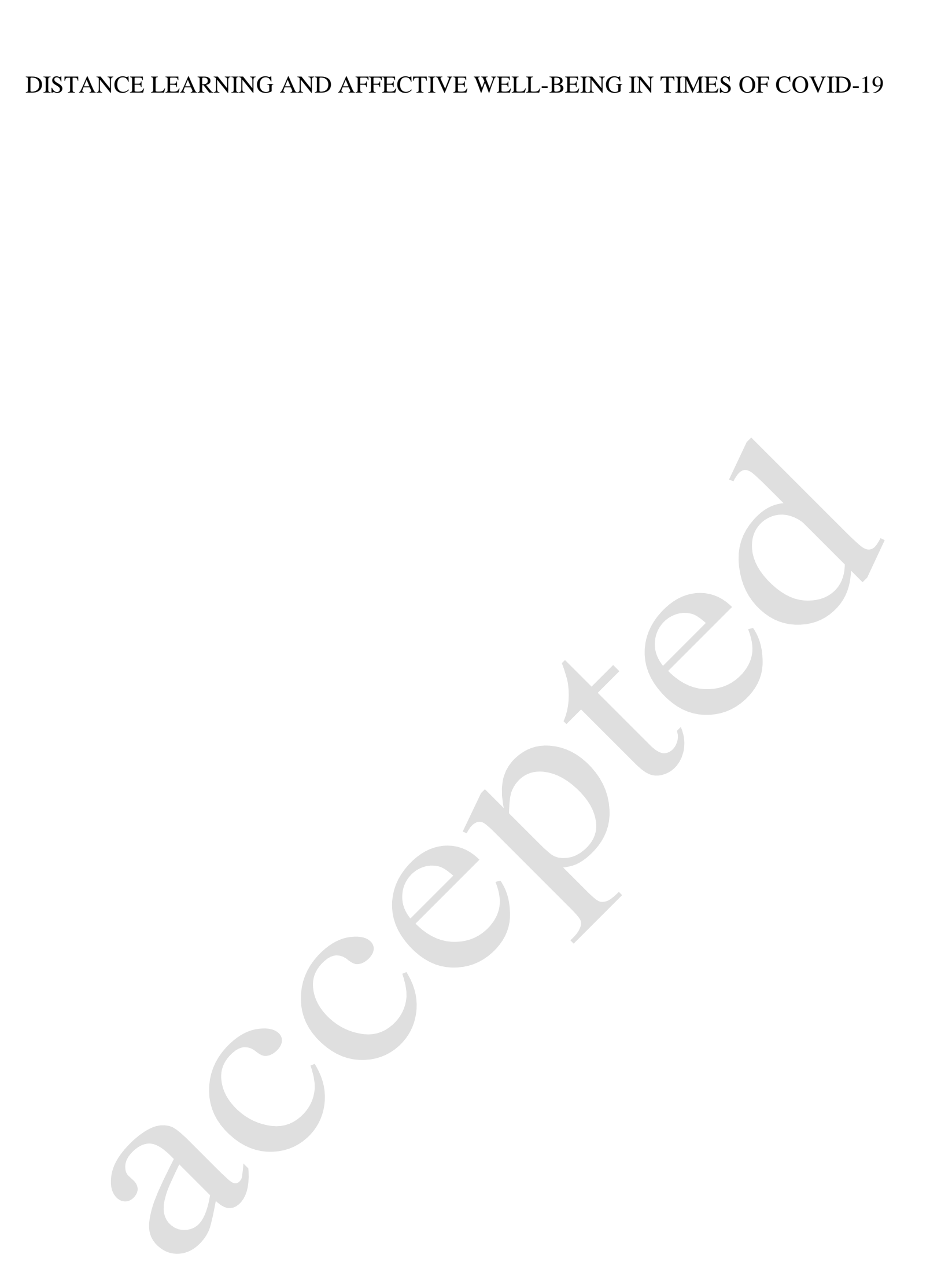


DISTANCE LEARNING AND AFFECTIVE WELL-BEING IN TIMES OF COVID-19

Draft version 6/14/21. Please do not copy without author's permission.

3 


\begin{abstract}
To slow down the spread of the COVID-19 virus, schools around the world were closed in early 2020, transferring children's scholastic activities to the homes and imposing a massive burden on parents and school-aged children. Using data of a 21-day diary study conducted between March and April 2020 in Germany, this work examined whether a) distance learning and b) parents' involvement therein were associated with negative parent-child interactions and affective well-being of parents and children, over and above the effect of daily stressors. Participants were 562 parents (489 mothers, $M_{\text {age }}=42.79, S D_{\text {age }}=6.12$, range $\left.=25-63\right)$ most of whom were married $(n=382,68.0 \%)$. They responded to the daily items with respect to the youngest child living in their household $\left(M_{\mathrm{age}}=9.74, S D_{\mathrm{age}}=2.81\right.$, range $\left.=6-19\right)$. On days when children were working on school tasks, parents reported more negative parent-child interactions as well as lower parental and child positive affect and higher child negative affect, but not higher parental negative affect. Moreover, days when parents were more heavily involved in learning (i.e., when children worked less independently) were days with more negative parent-child interactions, lower parental and child positive affect, and higher parental and child negative affect. Negative parent-child interactions were linked to lower affective well-being of parents and children, and partially accounted for the relation among daily stressors and affective well-being. The present work highlights the need for measures to better support school-aged children and their parents during distance learning.
\end{abstract}

Keywords: COVID-19; ambulatory assessment; homeschooling; parent-child dyad; affective well-being; daily stressors; 
DISTANCE LEARNING AND AFFECTIVE WELL-BEING IN TIMES OF COVID-19

\section{Distance Learning, Parent-Child Interactions, and Affective Well-Being of Parents and Children During the COVID-19 Pandemic: A Daily Diary Study}

In 2020, governments around the globe initiated various stages of lockdown that involved restrictions to people's regular lifestyles aiming to decelerate the spread of the novel coronavirus disease 2019 (COVID-19). Among these regulations, most schools and child care facilities worldwide were closed by the end of March 2020, affecting about 1.5 billion students (UNESCO, 2020). However, education did not intermit for the time of school closures, but was rather transferred to the families at home: Teachers delivered educational materials via e-mails, for instance, and children worked on these tasks needing more or less constant supervision and support by their parents (Huber, 2020). As, additionally, many parents were working from home, balancing telecommuting with full-time childcare and education constituted a particular challenge for families with school-aged children. Given that parents and children were facing an unprecedented situation including detrimental changes of the everyday routines of family life (Brown et al., 2020; Prime et al., 2020), the present study examined on a day-to-day basis whether distance learning and parental involvement therein were associated with negative parent-child interactions as well as parent-reported positive and negative affect of themselves and their children above and beyond daily stressors during the COVID-19 pandemic. This study was conducted in Germany between $28^{\text {th }}$ of March and $27^{\text {th }}$ of April 2020, during which the stringency index in this country (reflecting the number and strictness of lockdown policies that restrict individual's behavior) was 76.85 on a scale from 1 to 100 (Hale et al., 2020). This index in Germany was driven by nationwide school closures, workplace closures in some sectors, restrictions on gatherings to fewer than 10 people, but no measures of restricting public transport, for instance. Germany had a high number of COVID-19 cases and the measures imposed by the German government to counteract the spread of the virus were neither particularly lenient nor particularly strict 
compared to other countries (see Figure in the Online Supplement S1, showing COVID-19 cases plotted against stringency index across 166 countries worldwide).

\section{Stress and Parenting During Crises}

It has been emphasized that child and adult functioning are generally intertwined in families (Schermerhorn et al., 2010). In the face of community traumata, previous research has shown that parents' perceived distress is interrelated with their children's distress, wellbeing, and adjustment (e.g., Chemtob et al., 2010; see Eltanamly et al., 2019, for a metaanalysis). For instance, parental posttraumatic stress following a major earthquake was

significantly related to children's distress (Juth et al., 2015). Similarly, after the 2013 Boston Marathon bombing, higher caregiver distress was associated with greater child posttraumatic stress (Kerns et al., 2014). Recent research examining the impact of the COVID-19 pandemic on families suggests that well-being of parents was lower during the pandemic than before (Germany: Huebener et al., 2020; Australia: Westrupp et al., 2020; UK: Daly et al., 2020; US: McCrory Calarco et al., 2020) and that stress was higher than before (e.g., due to balancing work, distance learning, and full-time child care; see Hiraoka \& Tomoda, 2020). Furthermore, parental distress was linked to harsh parenting and lower parent-child closeness (Campbell et al., 2020; Chung et al., 2020) as well as negative child outcomes such as conduct problems, hyperactivity, and emotional problems (Romero et al., 2020).

In view of the particular circumstances of the COVID-19 pandemic, we examine in this work whether distance learning and parents' involvement therein, both potentially being a stressor on their own, pose a particular challenge to parent-child interactions and to children's and parents' daily well-being.

\section{COVID-19-Induced Distance Learning}

Attending functional schools has been found to represent a protective factor in the face of crises, as it provides children with an adaptive environment including rules and 
routines, and with the opportunity to interact and play with peers, for instance (Ager et al., 2010; Betancourt et al., 2010). In Germany, attending school is mandatory for all children (i.e., compulsory education) and it is not allowed that parents teach their children at home. However, during the COVID-19 pandemic, schools were closed and learning shifted from inperson classes to distance learning, representing an unprecedented situation for families in Germany (Huber et al., 2020). Schooling children at home required a form of parental school involvement that was entirely novel for all involved parties (i.e., teachers, parents, students): Parents had to replace in-person classes and create a remote learning environment for their children. A large survey with parents of school-aged children in Germany revealed that only $15.4 \%$ of parents in Germany indicated that teacher(s) provided videos to support their students (Wildemann \& Hosenfeld, 2020). Furthermore, 78\% of parents in Germany, Austria, and Switzerland reported that teachers did not use live webinars to get into contact with their students (Huber et al., 2020). A study comparing the implementation of distance learning during COVID-19 in seven European countries (Belgium, Germany, Italy, Netherlands, Spain, Sweden, United Kingdom) demonstrated that in Germany, students only spent about $5 \%$ of their distance learning time in contact with a teacher (e.g., live webinars), which was significantly lower than in all other countries except the UK (Thorell et al., 2021). By contrast, children spent about $34 \%$ of their distance learning activities in contact with a parent (Thorell et al., 2021), demonstrating that parents were greatly involved in their children's distance learning (e.g., by structuring learning hours, supervising children's learning process, and providing children with the support needed to complete the assigned tasks). As a result, parental time investment in children's scholastic activities in Germany increased considerably from before to during COVID-19-related school closures: The number of parents investing a maximum of one hour per day decreased from $72.5 \%$ before to $24 \%$ during the pandemic, with $76 \%$ of parents investing more than one hour per day during COVID-19-related school 
closures (Wildemann \& Hosenfeld, 2020). Yet, there were differences between families in the amount of parental involvement in distance learning (Huber et al., 2020), but also variation within families in the amount of required parental support from one day to the next (Blume et al., 2021).

While some types of parental involvement were shown to be positively related to children's outcomes (e.g., parents' participation at school), parental homework involvement has been shown to be negatively associated with children's academic achievement (Barger et al., 2019). Examining the effects of homework involvement on parental affective well-being, Pomerantz et al. (2005) found that on days when children had homework (vs. days without homework), mothers reported elevated negative affect while interacting with their children. On days mothers assisted their children a lot with homework, their negative affect was found to increase even more. The data further suggested that mothers' negative mood was not affected by the provision of assistance per se, but rather by the perception of children as helpless in doing their homework. Notably, mothers' positive affect was not linked to the occurrence of homework (Pomerantz et al., 2005). Consistent with these findings, further research indicated that homework stress predicted heightened negative affect in both, children and parents, but was unrelated to children's or parents' positive affect (Katz et al., 2012). Recent research suggests that while taking care of children during COVID-19 was beneficial for affective well-being, homeschooling children was associated with reduced affective wellbeing (Lades et al., 2020). In fact, parents of children who struggled with COVID-19-induced distance learning reported decreases in mental health (i.e., increases in anxiety and depression; Davis et al., 2020). By contrast, Janssen et al. (2020) found neither helping children with school nor any other assessed pandemic-related characteristics to predict the documented increase in daily negative affect of parents from before to during the pandemic. However, the authors highlighted the heterogeneity in their data, suggesting that families 
differed substantially in how well they dealt with the circumstances (Janssen et al., 2020). Further highlighting between-family differences, McCrory Calarco et al. (2020) found that, for some mothers, increased parenting time during COVID-19 was associated with increased stress, anxiety, and frustrations with their child, while other mothers experienced the additional parenting time as beneficial and joyful.

Altogether, schooling children at home during COVID-19 might have exceeded the stress associated with parental homework involvement during regular times, potentially bringing about deteriorations of the quality of daily parent-child interactions and affective well-being of parents and children. However, there seem to be considerable differences between families in how well they master the challenges associated with COVID-19-induced school closures.

\section{Parent-Child Interactions and Development}

Research examining the consequences of distance learning on parent-child interactions and affective well-being during the COVID-19 pandemic is paramount, as the family system constitutes one of the most important contexts shaping child development (Bronfenbrenner, 1986). In particular, the parent-child relationship has been identified as being crucial for children's well-being and healthy adjustment (see Collins \& Steinberg, 2006; Laursen \& Collins, 2009, for reviews). For instance, the parent-child relationship quality longitudinally predicted children's depressive symptoms (Boutelle et al., 2009; Branje et al., 2010), and parental emotional warmth was longitudinally related to lower child externalizing problems (Sentse et al., 2009). The parent-child relationship quality has further been found to predict children's adjustment 15 years later (e.g., depressive symptoms; Raudino et al., 2013). Going beyond children's psychological functioning and adjustment, research has demonstrated that the quality of parent-child interactions is linked to children's prosocial orientation and positive peer relationships (Clark \& Ladd, 2000) as well as to 
academic outcomes such as school readiness and achievement (Estrada et al., 1987). Recent work on the COVID-19 pandemic has further shown that family factors (e.g., family cohesion, parental mental health, parent-child COVID-19 communication) are associated with change in mental health of children (Whittle et al., 2020) and that increased conflict with parents predicted increases in depressive symptoms of adolescents and decreases in life satisfaction from before to during the pandemic (Magson et al., 2020), underlining the potential impact of the pandemic on children's well-being and development.

\section{The Present Study}

This study aimed to deepen our understanding of the interplay of COVID-19-induced distance learning, the parent-child relationship quality, as well as parental and child affective well-being in families' everyday lives. Specifically, it examined how parent-reported daily stressors, distance learning and the amount of parental involvement therein, negative parentchild interactions, as well as children's and parents' daily positive and negative affect are interrelated. For this purpose, an online 21-day diary study with parents of school-aged children was conducted between end of March and end of April 2020 in Germany. We hypothesized that days when parents reported stressors would be days with more negative parent-child interactions and lower affective well-being (i.e., higher negative and lower positive affect) of parents and children (H1a). We expected the same pattern of associations on the between-person level, meaning that parents who, on average across all assessments, experienced more stressors would report more negative parent-child interactions and lower affective well-being of parents and children (H1b). Furthermore, we expected that days with distance learning would be associated with more negative parent-child interactions and lower affective well-being of children and parents, above and beyond the effect of daily stressors (H2a). That is, days when children were required to work on school-related tasks during the COVID-19-induced distance learning period were hypothesized to be days with more 
negative outcomes compared to days when children were not working on school tasks. The same pattern of associations was hypothesized on the between-person level (H2b). In addition, we expected that the amount of parental involvement in children's scholastic activities would play an important role: Higher parental involvement in their children's distance learning was expected to be associated with deteriorated parent-child interactions and affective well-being of parents and children on the within-person level (H3a) and between-person level (H3b). Furthermore, we hypothesized a more negative parent-child relationship to be associated with lower positive affect and higher negative affect in both, parents and children on a within-person level (H4a) and between-person level (H4b). Based on research showing that daily parent-child conflict mediates the link between specific daily stressors (i.e., interparental conflict) and well-being (i.e., emotional distress; Chung et al., 2009), we also tested if negative parent-child interactions accounted for (part of) the association of both stressors (H5) and COVID-19-induced distance learning (H6) with children's and parents' affective well-being on the within-person level (H5a and H6a) and between-person level (H5b and H6b).

\section{Method}

The current data were collected within the PACO study (Psychological Adjustment to the COVID-19 pandemic), a comprehensive study addressing the adjustment of parents of schoolchildren to the restrictions imposed to slow down the spread of the coronavirus. The study consisted of a baseline assessment, a 21-day diary period, and a post assessment after the daily diary period. As a detailed description of all variables can be found online (https://osf.io/ugkj2/), only measures relevant to the present work are reported here. All data and analysis code necessary to reproduce the results reported here as well as a detailed study protocol can be found in the Open Science Framework (https://osf.io/ugkj2/). 
DISTANCE LEARNING AND AFFECTIVE WELL-BEING IN TIMES OF COVID-19

\section{Participants}

The initial sample comprised of 970 participants who at least partially completed the baseline assessment. Inclusion criteria for study participation were that participants needed to be (1) 18 years or older and (2) living with at least one school child in the same household at the time of the assessments. For the present analyses, only those participants who signed up for the daily diary part and completed at least one daily assessment were included, yielding an analytic sample of $N=562$ participants $\left(M_{\text {age }}=42.79, S D_{\text {age }}=6.12\right.$, range $\left.=25-63\right)$, most of whom $(n=489,87.0 \%)$ were female. These participants were predominantly married $(n=$ $382,68.0 \%)$, living with their non-marital partner in one common household $(n=64,11.4 \%)$, or separated / divorced $(n=64,11.4 \%)$. The remaining participants were single $(n=28$, $5.0 \%)$, with a partner, but living in separate households $(n=14,2.5 \%)$, or widowed $(n=9$, $1.6 \%)$. Most parents $(n=301,53.6 \%)$ reported that there were two children living in their household, and the average number of children living in the household was $2.06(S D=0.82)$. Most participants $(n=344,61.2 \%)$ reported a University degree as their highest degree. Approximately half of participants reported a net monthly household income of $4000 €$ or more $(n=277,49.2 \%), 116$ participants $(20.6 \%)$ reported monthly income between $3000 €$ and $4000 €$, and 128 participants (22.8\%) below $3000 €$ (41 participants did not provide information on income).

We also asked parents about information on the youngest child in the household, who attended school in the school year of the time of assessment. These target children were on average 9.74 years old $(S D=2.81$, range $=6-19)$, and the gender proportion was approximately even (268 girls, 290 boys, 4 no information). Most children attended elementary school $(n=367,65.3 \%)$ or the academic tier of secondary school (Gymnasium; $n$ $=135,24.0 \%)$. 


\section{Procedure}

The PACO study comprised a baseline assessment, a 21-day diary period, and a post assessment. All assessments were implemented as online questionnaires on soscisurvey.de. Participants could enroll for the study between March 27, 2020 and April 3, 2020 by providing informed consent and filling in the baseline questionnaire. At the end of this baseline assessments, participants could sign up for the other study parts. Those who did, received daily questionnaires for the following 21 days. E-mails containing the link to the daily questionnaire were sent out at $7 \mathrm{pm}$ each day and participants were requested to complete the survey before going to bed. Questionnaires were deactivated at 5 am the next morning. The third study part, a post assessment, took place the day following the daily diary period. Among all participants completing the baseline assessment, 40 retail vouchers $(50 €$ each) were raffled. When taking part in the daily diary period, participants could enter another lottery for 3 iPads and 100 retail vouchers (50€ each). They received one ticket for the lottery when completing a daily questionnaire and two tickets when completing the post assessment. Study participation was voluntary and could be terminated at any time. The study was approved by the Ethics committee of the DIPF | Leibniz Institute for Research and Information in Education (Study "Psychologische Anpassung an die Corona-Pandemie"). Participants (at least partially) completed 7,747 diaries, corresponding to a compliance rate of $65.6 \%$ (maximum number of data points $=562$ participants $\mathrm{x} 21$ days $=11,802$ ). Seventyfour participants did not complete any daily measures after the first study week. Among the 488 participants who provided at least one assessment after the first study week, compliance was $73.8 \%$.

\section{Measures}




\section{Daily Measures}

Distance Learning. Participants were asked whether their child had received learning material or school work from their school / teachers at that day ("Did your child receive learning materials or tasks from school today?"). In the first week of the study, some participants informed us (using open response formats in the daily online questionnaires) that their children did not receive materials on a daily basis, but were provided with a work package for a week or longer. Therefore, we changed this item to "Has your child worked on materials or tasks today for school? This either refers to tasks designed for this particular day, or tasks that can be worked on over several days" on April 6 (study day six for the majority of participants). Distance learning was assessed at the weekend and during public holidays as well, because homework assignments could also be provided for those days. Response options were "yes" (coded as 1), "no" (coded as zero), and "do not know" (coded as missing value).

Parental Involvement. The degree to which parents were involved in distance learning was assessed with two items measuring the degree to which children learned independently or needed parental help: "My child worked on the learning material or tasks without problems today, on his/her own." and "My child needed a lot of support while working on the learning material or tasks today.”. These items were answered on a 7-point Likert scale $(1=$ "completely disagree" to $7=$ "completely agree"), with responses to the first item being recoded so that higher scores indicated more parental involvement in learning. The two items were correlated on both the within-person level, $r=.703$, and on the betweenperson level, $r=.934$. Responses to the two items were averaged per participant and day. We note that the responses on these items have been reported as capturing learning independence in different work using the data from the same sample (Blume et al., 2021). We chose to reverse code the responses and to use reverse coded daily learning independence as a measure 
of daily parental involvement in order to remain consistent with prior work in this area that has targeted parental assistance as predictor of child and parental well-being (Pomerantz et al., 2005).

Stressor Occurrence. Based on previous work (Almeida et al., 2002; Brose et al., 2011), parents indicated whether any of the following events, that people could find irritating or disturbing, had occurred on that day (1 = "no"; 2 = "yes"): argument or disagreement; negative event involving a friend or family member; negative health-related event; negative work-related event; negative event in the household; negative event during leisure time; negative event involving financial problems; other negative event. A dichotomous variable was created for each participant and day, indicating whether at least one stressor had occurred on this day (coded as 1$)$ or not (coded as 0$)$.

Negative Parent-Child Interactions. Using on a 7-point Likert scale $(1=$ "completely disagree" to $7=$ "completely agree"), participants indicated whether (1) they found it hard to assert themselves with respect to their child on that day; (2) they found that taking care of their child was exhausting on that day; (3) they had disagreements with their child on that day. Responses to the three items were averaged per participant and day. Internal consistency, estimated as multilevel McDonald's $\omega$ (Geldhof et al., 2014), was estimated as .75 (within) and .92 (between).

Parental Affect. Participants rated the extent to which they experienced each of eight emotional states on that day (afraid, angry, sad, worried, happy, cheerful, balanced, and relaxed). The items were answered on a 7-point Likert scale $1=$ "not at all" to 7 = "very"). Daily parental positive affect was computed as the average of the four items happy, cheerful, balanced, and relaxed $(\omega=.86$ (within) / .94 (between)), and daily parental negative affect was computed as the average of the items afraid, angry, sad, and worried ( $\omega=.68$ (within) / .89 (between)). 
Child Affect. Parents also indicated the extent to which their child had experienced emotional states on that day. We used the same items for the assessment of parental affect and computed daily child positive affect $(\omega=.84$ (within) / .91 (between)) and daily child negative affect $(\omega=.66$ (within) / .87 (between)) as the average of four items each.

\section{Covariates}

We controlled for a set of covariates in all models. On the person level, we included the target child's age (in years), gender (coded as 0 for girls, 1 for boys), and school type (with the academic tier of secondary school coded as 0 , and all other school types as 1 ), the number of children living in the household, parental relationship status (coded as 1 for participants who were married or in a permanent relationship, 0 otherwise), working hours (two dummies coding if participants worked full time or part time at the beginning of March 2020), and current employment situation. We assessed parental employment situation with three items inquiring about their employment status in early March 2020, whether and how their employment status had changed due to the COVID-19 pandemic, and where they pursued their employment (i.e., from home or outside the home). Responses to these three items were combined into one variable coding participants' current employment situation: unemployed ( $n=88$ ), currently working outside the home $(n=137)$, working from home, but having already worked from home before the COVID-19 pandemic $(n=33)$, or changed to working from home in response to the COVID-19 pandemic $(n=302)$. For the following analyses, three dummy variables were created that were coded as 1 , if participants were currently unemployed, worked outside their home, or worked from home and had been working from home before the pandemic, respectively (0 otherwise). Hence, participants who were working from home but had not worked from home before the pandemic served as the reference category in the analyses. On the daily level, we controlled for whether or not the current day was a regular school day. The variable school day was coded as zero on 
weekends and on all assessments occurring on public holidays or during the Easter vacation (coded 1 on regular weekdays outside the Easter vacation). Since start and end of the Easter vacation varied by federal state, we determined these dates via participants' zip codes. Consequently this covariate is missing for participants who did not enter a (valid) zip code ( $n$ $=10)$.

\section{Data Analyses}

We used multilevel models to analyze the daily diary data, given the nested data structure with daily observations (Level 1) nested within participants (Level 2). In a first step, five multilevel models were estimated with one of the following variables as dependent variables: negative parent-child interactions (Model 1a), parental positive affect (Model 2a), parental negative affect (Model 3a), child positive affect (Model 4a), and child negative affect (Model 5a). In all of these models, the dichotomous variables daily stress and daily distance learning were centered on their person means (i.e., each participants' proportion of days with stressors and distance learning, respectively) and included as Level-1 predictors. The person means of these variables were grand-mean centered and added as Level-2 predictors. With this procedure, the estimated effects of the Level-1 predictors are pure estimates of the respective within-person effects and the estimated effects of the Level-2 predictors are pure estimates of the respective between-person effects (Wang \& Maxwell, 2015). Child gender and school type, as well as parental relationship status, the two working hours dummies, the three parent employment dummies and school day were entered as dichotomous variables (coded 0/1). Child age was centered on 10 years, number of children was coded continuously with one child coded as 0 . Random effects for the two Level-1 predictors were estimated to allow for the within-person effect of stressors and distance learning to vary across participants; all random effects (the two slopes and the intercept) were allowed to covary. 
In the second step, we replaced the predictor distance learning by daily parental involvement (Level-1 predictor centered on the person mean and Level-2 predictor centered on the grand mean). Note that this variable was only assessed on days when parents reported that their child had worked on school-related tasks today (only if distance learning $=1$ ). The five multilevel models estimated in the first step were then re-estimated with this predictor (Models 1b-5b).

In a last step, we tested if the postulated effects of distance learning and stressor occurrence on parents' and children's affect might partially be accounted for by daily parentchild interactions. To that end, we estimated a multilevel mediation model in Mplus (see Figure 1). Random slopes were estimated for all central Level-1 effects in the model (i.e., the a-paths $=$ effects of stressors and distance learning on parent-child interactions; the b-paths = the effects of parent-child interactions on the four affective well-being measures; and the direct effects of stressors and distance learning on the four affective well-being measures); we also estimated the covariances among the six a- and b-paths. The eight indirect effects on the within-person level were estimated as $a * b+\operatorname{cov}_{a b}$, where $\operatorname{cov}_{a b}$ represents the covariance of the two random effects (see Kenny et al., 2003; Preacher et al., 2010). An analogous mediation model was also estimated at the between-person level. Here, the indirect effects were estimated as the product of the two corresponding regression coefficients. For these analyses, we used the Bayesian estimator in Mplus, which enables latent person-mean centering of the dichotomous predictors (stress, distance learning) that is required to yield unbiased estimates of within- and between-person mediation effects (Asparouhov \& Muthén, 2019).

Multilevel models were estimated with the nlme package (Pinheiro et al., 2019) in R using restricted maximum likelihood estimation and the packages default estimation of degrees of freedom. For the multilevel mediation model, the Mplus default (diffuse) priors 
were used for the analyses. Two Markov Chain Monte Carlo (MCMC) chains were employed with a $50 \%$ burn-in, 3000 iterations, and a thinning factor of 50 .

\section{Results}

Table 1 depicts descriptive statistics of the main study variables.

\section{Multilevel Models}

The results of the multilevel models are presented in Table 2. Supporting H1a, we found that on days when parents reported the occurrence of at least one stressor, they reported more negative parent-child interactions, $b=.728, p<.001$, lower parental positive affect, $b=$ $-.730, p<.001$, higher parental negative affect, $b=.759, p<.001$, lower child positive affect, $b=-.457, p<.001$, and higher child negative affect, $b=.407, p<.001$. In line with H1b, statistically significant associations of stressors with these variables were also found on the between-person level. Largely supporting $\mathrm{H} 2 \mathrm{a}$, the analyses showed that on days when children were working on school tasks, parents reported more negative parent-child interactions, $b=.202, p<.001$, lower parental positive affect, $b=-.150, p<.001$, lower child positive affect, $b=-.189, p<.001$, and higher child negative affect, $b=.068, p=.009$. Partially contrary to our expectations in $\mathrm{H} 2 \mathrm{a}$, parental negative affect was not higher on days with distance learning compared to days without distance learning, $b=.053, p=.070$.

Contrary to $\mathrm{H} 2 \mathrm{~b}$, distance learning was not significantly associated with any of the dependent variables on the between-person level, $p>.164$ for all.

Considering the effects of covariates included in the models reported in Table 2, we found that on school days compared to weekends or days during the Easter vacation, parents reported worse parent-child interactions, $b=.224, p<.001$, lower parental $b=-.169, p<$ .001 , and child positive affect, $b=-.127, p<.001$, and higher parental, $b=.067, p=.018$, and child negative affect, $b=.069, p=.006$. Covariates at the between-person level had the following effects: When the youngest school-aged child in the household was a boy 
(compared to a girl), parents reported worse interactions with this child, $b=.198, p=.010$, lower parental positive affect, $b=-.158, p=.042$, and lower child positive affect, $b=-.182, p$ $=.006$. Parents of older children reported less negative parent-child interactions, $b=-.059, p$ $=.001$ than parents of younger children. Compared to parents who worked outside their home before the pandemic and worked from home in response to the pandemic, parents working outside their home reported less negative parent-child interactions, $b=-.211, p=.026$, as well as less parental, $b=-.221, p=.016$, and child negative affect, $b=-.233, p=.002$. Participants who were married or in a permanent relationship reported lower parental, $b=$ $.220, p=.036$, and child negative affect, $b=-.216, p=.009$.

When considering only days when children worked on tasks for school, findings supported H3a, suggesting more negative outcomes on days when parents were more involved in children's distance learning (see Table 3). Specifically, days with more parental involvement (i.e., less independent learning of children) were days with more negative parent-child interactions, $b=.207, p<.001$, lower parental positive affect, $b=-.068, p<$ .001 , higher parental negative affect, $b=.052, p<.001$, and lower child positive affect, $b=-$ $.133, p<.001$, as well as higher child negative affect, $b=.093, p<.001$. The same pattern of associations emerged on the between-person level, supporting H3b.

\section{Multilevel Mediation Model}

Visually inspecting the trace plots and autocorrelation plots of the parameter estimates suggested that the two MCMC chains converged successfully (maximum potential scale reduction $=1.002)$. Results of the multilevel mediation model are summarized in Table 4 and Figure 1. As can be seen in this figure, our findings supported $\mathrm{H} 4 \mathrm{a}$ and $\mathrm{H} 4 \mathrm{~b}$, as negative parent-child interactions were linked to higher parental and child negative affect and to lower parental and child positive affect on both, the within- and between-person level. 
The total effects of daily stressor experience on the four outcome variables (parental and child affective well-being) were statistically meaningful on both the between-person level and the within-person level. Furthermore, both the direct effects and the indirect effects were statistically meaningful. Together, these results are in line with H5a and H5b, assuming that part (but not all) of the effects of daily stressors on both parental and child affective wellbeing can be accounted for by negative parent-child interactions. The proportions of indirect effect to total effect were larger for child well-being (within: $48.3 \%$ and $39.2 \%$; between: $87.2 \%$ and $69.8 \%$ ) than for parental well-being (within: $15.3 \%$ and $6.7 \%$; between: $53.3 \%$ and $40.1 \%$ ), suggesting that stress has a relatively stronger direct effect on parental than on child well-being.

Considering distance learning, we did not find effects on the outcome variables on the between-person level (see also Table 2). On the within-person level, all indirect effects of distance learning were statistically significant, except the indirect effect on child positive affect. However, only the total effect on child positive affect was statistically meaningful, $b=$ -.076 [-.114, -.037]. Hence, H6a and H6b were not supported by the data, as there was no consistent evidence for indirect effects of distance learning on any of the four well-being measures via negative parent-child interactions on either the within-person level or the between-person level.

\section{Supplementary Analyses}

Random variance associated with the effects of stressors and distance learning on the outcome variables (see Table 2) suggested that the within-person effects of these two variables differed across participants. Figure 2 depicts the heterogeneity of the within-person effects of distance learning on the five outcome variables across participants (see Online Supplement S2 for heterogeneity in the effects of stress). This figure illustrates that the observed heterogeneity in the effects of distance learning was more pronounced for the 
outcomes negative parent-child interactions and negative affect: Whereas for $91 \%$ of all participants, the estimated effect of distance learning on child and parental positive affect was in the same direction as the fixed effect, the proportions were somewhat lower for negative parent-child interactions (82\%), child negative affect (82\%), and parental negative affect (74\%). This suggests that not only the size, but also the direction of the effect of distance learning may differ across families - in particular for negative outcomes (negative parentchild interactions, negative affect). We note, however, that the point estimates of these person-specific effects are contaminated with measurement error (Liu et al., 2021; Neubauer et al., 2020) and therefore need to be interpreted carefully. By contrast, there was almost no variation in the direction of the effects of stress on the five outcome variables across participants (see Online Supplement S2), indicating that all participants reported increased parental negative affect and diminished parental positive affect, for instance, on days with elevated stress. Furthermore, estimated correlations between person-specific regression coefficients of the effects of distance learning vs. stress on the five outcomes were relatively small (range: -.14 to .32; see Online Supplement S3), suggesting that individuals' affect was differentially associated with distance learning and stressors.

Conducting a number of purely explorative analyses, we examined if these differences in within-person associations were related to child age, child gender, school type, parental working hours, parental relationship status, parental employment status, or the proportion of days with stressors or distance learning. Given the large number of exploratory tests, we applied a more stringent $\alpha$-level of .01 to all tests to avoid excessive Type-I error inflation. None of the 130 cross-level interaction effects was significant $(p>.027$, for all).

Based on the unexpected finding that distance learning exhibited significant effects on negative parent-child interactions on the within-person level, but not on the between-person level, whereas stress showed the same pattern of significant effects on both levels, we 
conducted additional analyses. Potentially both, too much distance learning and too little distance learning might be maladaptive for the parent-child relationship, with too much distance learning overburdening children and parents, and too little distance learning indicating no support on part of the schools during school closings. We therefore explored whether the effects of distance learning on parent-child interactions might be quadratic on the between-person level. These analyses revealed a significant quadratic effect of distance learning on negative parent-child interactions (see Figure 3), $b=1.572, p=.008$, but no significant quadratic effect of stress, $b=.243, p=.609$, suggesting that parent-child interactions were worse in families with distance learning on (almost) no days or on (almost) all days compared to families who reported distance learning on a subset of days.

Lastly, since the stressor variable included instances of arguments or disagreements with others, associations with negative parent child-interaction might have been inflated if parents coded conflicts with their children as one of these stressors. We therefore repeated the analysis with a new stressor variable that did not include arguments or conflicts, negative events involving a friend or family member, negative events in the household, and negative events during leisure time. This did largely not alter the pattern of results, however, with three exceptions: the within-person effect of distance learning on parental negative affect (Model 3a) was now also statistically significant, $b=.067, p=.026$. Further, in the mediation model (in which stressors and distance learning were also entered simultaneously), the total and indirect effects of distance learning on both parental and child positive affect on the within-person level were significantly negative in these sensitivity analyses. The indirect effects of stress on parental positive and negative affect were no longer statistically meaningful. 
DISTANCE LEARNING AND AFFECTIVE WELL-BEING IN TIMES OF COVID-19

\section{Discussion}

The present study examined how distance learning and parents' involvement therein was associated with parent-child interactions as well as parents' and children's affective wellbeing during COVID-19-related school closures in Germany.

On days when children worked on school tasks at home, parents indicated more negative parent-child interactions as well as higher child negative affect and lower parental and child positive affect (H2a). This means that, irrespective of how much parents were involved in children's daily learning at home, days with distance learning were days on which parents had difficulties to assert themselves against the child or reported more disagreements with the child, for instance. Giving another example, on these days, parents indicated that they and their child were less happy, cheerful, balanced, and relaxed, and that their child also experienced more anxiety, sadness, anger, and worries than on days without distance learning. However, there was no significant link between distance learning and parental negative affect, suggesting that when children worked on school tasks, their mother or father did not necessarily report higher feelings of, e.g., anger or sadness that day.

Considering children's dependence on parents when completing school tasks, we found that higher parental involvement in children's distance learning was linked to more negative outcomes, that is, worse parent-child interactions, higher parental and child negative affect, and lower parental and child positive affect. We consistently found these effects on the within-person (H3a) and between-person level (H3b). These findings are consistent with prior studies showing that parental involvement in homework (and distance learning; Lades et al., 2020) is linked to heightened negative affect in parents (Pomerantz et al., 2005) and children (Katz et al., 2012). However, while parental homework involvement was not linked to positive affect of parents or children in these prior studies, the present work demonstrated that distance learning (vs. no distance learning) as well as parental involvement therein were 
negatively associated with both, parental and child positive affect. Moreover, when controlling for the interrelations among parents' and children's affective well-being, only the effect of distance learning on children's positive affect remained significant (see total effect estimates in Table 4), suggesting that this was the most robust effect. Taken together, these results imply that being partly responsible for the education of one's children is more globally linked to the affective well-being of parents and children than the lighter version of assisting children in completing their homework.

Notably, the within-person effects of distance learning and parental involvement therein on negative parent-child interactions and affective well-being emerged over and above the effects of general daily stressor occurrence. As the stressor variable comprised also events that potentially involved the child (e.g., arguments or conflicts, negative events in the household), we performed sensitivity analyses excluding such events. In these analyses, the effect of distance learning on parental negative affect (which had been insignificant in the main analyses) was significant and positive. This indicates that when controlling for family stressors (that might be related to distance learning), distance learning per se was not associated with heightened negative affect in parents, but when controlling only for stressors that were non family-related (work, health, finances), distance learning was associated with increased negative affect in parents.

We found that on days when parents experienced stressors, they reported more negative parent-child interactions, higher parental and child negative affect, and lower parental and child positive affect (H1a). Finding parental stressors to be related to parental and child affective well-being on a daily basis supports previous work emphasizing the interrelations among parental and child functioning (Schermerhorn et al., 2010) and extends previous between-person research showing that parents' distress during crises spills over to their children (Chemtob et al., 2010; Eltanamly et al., 2019; Romero et al., 2020). 
On the between-person level, however, distance learning per se was not associated with any of the outcomes $(\mathrm{H} 2 \mathrm{~b})$, while stressor occurrence exhibited the same pattern as on the within-person level (H1b). Hence, parents who frequently experienced daily stressors across all assessments, reported more negative parent-child interactions and lower affective well-being of parents and children. By contrast, the average number of days with distance learning was not linked to the parent-child relationship quality or affective well-being, suggesting that distance learning cannot be equated with just another daily stressor. Further exploring this unexpected finding, we found evidence for a quadratic effect: Parent-child interactions were worse in families in which children worked on school tasks either very rarely during the study or on approximately all days of the study compared to families in which children worked on school tasks on a subset of days. Possible explanations for this finding might be that, on the one hand, children who nearly never worked on school tasks at home had to be cared for more intensively (e.g., to counteract boredom or to keep children out of mischief), which likely negatively affects the parent-child relationship. On the other hand, children who worked on school tasks almost every day potentially, in sum, needed more parental involvement in completing the tasks, which might also put strain on the parentchild relationship. Supporting this assumption, parent-child interactions on average were more positive when children worked on school tasks very independently.

Previous research showed that parental stress (e.g., financial strain) is linked to a more negative parent-child relationship quality (Chung et al., 2020) and that the quality of parentchild interactions is associated with subsequent changes of child well-being (Branje et al., 2010; Sentse et al., 2009). Building upon this, we tested whether negative parent-child interactions were linked to lower affective well-being of parents and children (H4), and whether the effects of distance learning and stressors on parental and child affective wellbeing might (in part) be mediated by negative parent-child interactions ( $\mathrm{H} 5$ and H6). On the 
within-person (H4a) and between-person level (H4b), negative parent-child interactions were associated with higher child and parental negative affect and lower child and parental positive affect. Furthermore, we found indirect effects of daily stressors on affective well-being of both parents and children on both levels ( $\mathrm{H} 5 \mathrm{a}$ and $\mathrm{H} 5 \mathrm{~b})$. This pattern of results is consistent with the assumption that negative parent-child interactions might in part mediate the effects of stressors on parental and child well-being. Examining the proportion of indirect to total effect, we found that parental stressor occurrence was primarily indirectly associated with child well-being in that it was related to negative parent-child interactions, which were, in turn, linked to lower affective well-being of children. In contrast, parental stressor occurrence was rather directly linked to parental well-being, without a strong mediation via parent-child interactions. Furthermore, sensitivity analyses revealed that when considering stressors exclusive of family stressors, parental stressor occurrence was only directly linked to affective well-being of parents, but not via parent-child interactions. In contrast, there was no consistent evidence for negative parent-child interactions to mediate the effects of distance learning on any of the four well-being outcomes on either the within-person (H6a) or the between-person level (H6b).

In exploratory analyses, we aimed at further understanding the differences between families in the daily links of distance learning and stressors with parent-child interactions and affective well-being. Supporting our notion that the effects of distance learning are distinguishable from those of daily stressors, we found larger differences between families in the effects of distance learning than in the effects of stressors on the five outcomes. That is, in almost all families, encountering a stressor was associated with more conflicts between parents and children and with parents having a hard time asserting themselves against their child, and with higher negative affect, for instance. By contrast, families differed more pronouncedly in whether distance learning was linked to better or worse parent-child 
interactions. For instance, while for $82 \%$ of families, distance learning was associated with worse parent-child interactions, it was associated with better parent-child interactions for $18 \%$ of families. This implies that distance learning is not a stressor per se, but might also represent a resource in some families (e.g., when distance learning works well, parents and children might have a good time together). These findings are consistent with heterogeneity in outcome patterns during COVID-19 documented in prior work (Janssen et al., 2020; McCrory Calarco et al., 2020). For instance, McCrory Calarco et al. (2020) showed that some mothers with increased parenting time reported lower well-being, whereas others experienced spending more time with their children as a source of joy. Further highlighting the differences between distance learning and parental stress, we found rather low correlations between either effects on the outcomes across families. For instance, in families in which parental stressor occurrence was strongly linked to negative parent-child interactions, distance learning was not necessarily linked to better or worse negative parent-child interactions.

Altogether, the present study illustrates one burden that lies on families as a result of school closures and associated distance learning during the COVID-19 pandemic.

Considering the importance of a good parent-child relationship for healthy child development and family functioning (Bronfenbrenner, 1986; Raudino et al., 2013; Sentse et al., 2009), the current findings emphasize the need for measures and interventions to decrease family strain during the COVID-19 pandemic and other crises alike. In the face of crises, well-regulated structures, roles, and routines at school (Ager et al., 2010; Betancourt et al., 2010) and within the family system (Crespo et al., 2013; Harrist et al., 2019) have been identified as protective factors associated with children's successful adaptation and well-being. Thus, to attenuate the downstream consequences of the disruptions of family life, parents should invest in developing new rituals and routines in daily life during the COVID-19 pandemic. In this regard, providing children with autonomy support might aid in improving parents' and 
family's adjustment to the pandemic (Neubauer et al., 2021). Besides, online interactions and/or live communication between teachers and students might decrease the burden of parents as replacing educators in the learning process of their children. As such, live contact hours were found to facilitate children's learning on their own (Bansak \& Starr, 2021) and research in different countries documented the importance of and parents' wish for more teacher-student and teacher-parent interactions and live communication (Harper et al., 2021; Miguel et al., 2021; Wildemann \& Hosenfeld, 2020). However, more than half of the queried school personnel in Germany indicated that schools are not (or rather not) technically sufficiently equipped for web-based schooling (Huber et al., 2020), highlighting the need to invest in a better digital infrastructure in the German educational system. Another possibility to support parents during times of distance learning would be to disseminate information about the learning process in general and how to assist children during school tasks (e.g., how to structure learning sessions or how to explain certain curricula). It is conceivable that increasing parents' knowledge in this matter might help to enhance parents' perceived support of schools and teachers, maximize the sufficiency of parental involvement in children's distance learning, and thus diminish the potential for parent-child conflicts.

\section{Limitations}

The present research is limited in several ways. First, it was conducted with a convenience sample of parents in Germany, limiting the generalizability of findings. Furthermore, the sample was positively selected (i.e., high education and high income), possibly because less well-off parents did not have time to complete the survey (see Romero et al., 2020). This may have led to an underestimation of the level of stress, as low-income and lower-middle class parents have been found to experience more instrumental and financial distress during COVID-19 (Chen et al., 2021). However, recent research indicates that especially high-income and education groups show diminished well-being during 
COVID-19 (Daly et al., 2021; Guo et al., 2021) and are more prone to experience stress over structuring and planning distance learning than parents with a lower socioeconomic status (Chen et al., 2021). Altogether, more research is needed to identify the possible differential effects that COVID-19-induced distance learning has on families with varying socioeconomic backgrounds.

Second, it further has to be considered that the present sample mainly consisted of women. Although there is evidence that mothers and fathers report highly similar parentchild interactions (Mastrotheodoros, Van der Graaff et al., 2020), previous research also suggests that mother-child and father-child relationships might be differently related to outcomes (Branje et al., 2010). Most likely, the interplay between maternal and paternal parenting is of importance as well (Meunier et al., 2012). Therefore, future research should assess mother-child and father-child interactions separately as well as include a specific measure of the mother-father relationship quality to shed further light on the daily interplay (and spillover) among these variables (see Gao \& Cummings, 2019).

Third, the present study was based on parent-report only, that is, children's positive and negative affect were reported by parents as well. Relations among variables that are reported by the same individual are likely overestimated (see Huang et al., 2019; Mastrotheodoros, Van Lissa et al., 2020). Therefore, in the present study, the association among parental and child affect and the associations between parent-child interactions and parental and child affect might be overestimated (perception bias).

Fourth, we focused on negative parent-child interactions in this work. Further research should include positive parent-child interactions as a potential resilience factor. As such, the restrictions associated with the COVID-19 pandemic (e.g., social distancing and home confinement) also provide opportunities for family members to spend more time together (Gambin et al., 2020). Future research should assess whether having a good time as a family 
by playing or cooking together, for instance, can serve as a buffer for negative parent-child interactions occurring during distance learning.

Fifth, the indirect effects in the mediation model can only be meaningfully interpreted in terms of a causal mediation model when assuming a temporal order of constructs and that there are no unobserved third variables accounting for the observed associations (no other common causes). Drawing such conclusions from observational data is difficult and requires knowledge of the causal network of variables. We attempted to control for these concerns by including potentially relevant covariates, but we note that there may of course be other relevant common causes that were not statistically controlled for in our analyses.

\section{Conclusion}

Worldwide school closures as a response to the COVID-19 pandemic have transferred children's scholastic activities to the homes. This required an increased amount of parental involvement in their children's education, during times when many parents were also struggling with other consequences of the pandemic (i.e., financial strain). The present findings highlight that the effects of distance learning diverge from those of daily stressors, indicating that distance learning is not just another daily stressor that is piled on parents during the school closures. Our findings suggest that on average distance learning and parental involvement therein were associated with more negative parent-child interactions and lower affective well-being of both, parents and children, but that there were noticeable differences between families in these effects. These findings emphasize the need for measures to increase the support for parents of school-aged children during times of distance learning. 
DISTANCE LEARNING AND AFFECTIVE WELL-BEING IN TIMES OF COVID-19

\section{Tables and Figures}

\section{Table 1}

Descriptive Statistics of the Main Study Variables

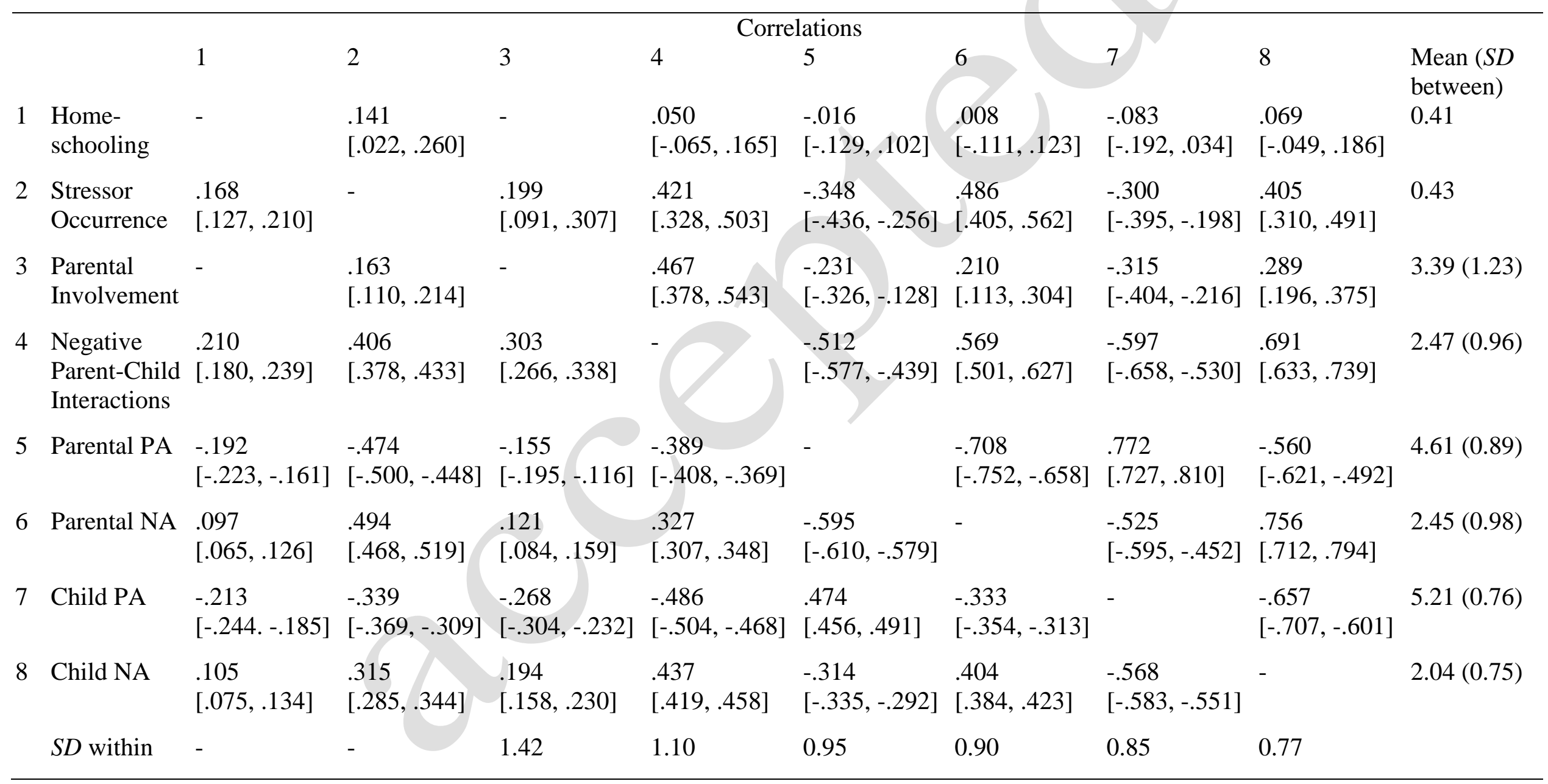


DISTANCE LEARNING AND AFFECTIVE WELL-BEING IN TIMES OF COVID-19

$\begin{array}{lllllllll}\text { ICC } & - & - & .430 & .430 & .470 & .542 & .445 & .485\end{array}$

Note. Two separate multilevel structural equation models were used to estimate the descriptive statistics: In the first model all variables except parental involvement were included, in the second model all variables except distance learning were included. Because parental involvement was assessed only on days with distance learning, the correlation between these two variables cannot be estimated. To estimate the correlations, a Bayesian estimator was used in these models in order to model distance learning and stressor occurrence as categorical variables. The numbers in square brackets therefore represent the $95 \%$ credible intervals of the correlations. Within-person correlations are depicted below the diagonal, between-person correlations above the diagonal. $\mathrm{PA}=$ positive affect; $\mathrm{NA}=$ negative affect. 
DISTANCE LEARNING AND AFFECTIVE WELL-BEING IN TIMES OF COVID-19

\section{Table 2}

Results of Multilevel Models With Distance Learning as Predictor

\begin{tabular}{|c|c|c|c|c|c|}
\hline & $\begin{array}{l}\text { Negative } \\
\text { Interactions } \\
\text { Model 1a }\end{array}$ & $\begin{array}{l}\text { Parental Positive } \\
\text { Affect } \\
\text { Model 2a }\end{array}$ & $\begin{array}{l}\text { Parental Negative } \\
\text { Affect } \\
\text { Model 3a }\end{array}$ & $\begin{array}{l}\text { Child Positive Affect } \\
\text { Model 4a }\end{array}$ & $\begin{array}{l}\text { Child Negative } \\
\text { Affect } \\
\text { Model 5a }\end{array}$ \\
\hline & \multicolumn{5}{|c|}{ Fixed Effects } \\
\hline Intercept & $2.236 *(.225)$ & $4.576^{*}(.226)$ & $2.517 *(.228)$ & $5.298 *(.194)$ & $2.035 *(.178)$ \\
\hline Within-person effects & & & & & \\
\hline Distance learning & $.202 *(.039)$ & $-.150 *(.031)$ & $.053(.029)$ & $-.189 *(.029)$ & $.068 *(.026)$ \\
\hline Stressor & $.728 *(.039)$ & $-.730 *(.029)$ & $.759 *(.029)$ & $-.457 *(.028)$ & $.407 *(.025)$ \\
\hline \multicolumn{6}{|l|}{ Between-person effects } \\
\hline Distance learning & $.137(.169)$ & $.009(.168)$ & $-.133(.168)$ & $-.201(.144)$ & $.031(.133)$ \\
\hline Stressor & $1.254 *(.137)$ & $-1.154 *(.136)$ & $1.633 *(.137)$ & $-.801 *(.117)$ & $1.028 *(.108)$ \\
\hline \multicolumn{6}{|l|}{ Covariates } \\
\hline School day ${ }^{\text {a }}$ & $.224 *(.035)$ & $-.169 *(.030)$ & $.067 *(.028)$ & $-.127 *(.027)$ & $.069 *(.025)$ \\
\hline Child age & $-.059 *(.018)$ & $-.009(.018)$ & $.009(.019)$ & $-.031(.016)$ & $-.014(.015)$ \\
\hline Child gender ${ }^{b}$ & $.198 *(.077)$ & $-.158 *(.078)$ & $.081(.078)$ & $-.182 *(.067)$ & $-.006(.061)$ \\
\hline $\begin{array}{l}\text { Number of children } \\
\text { in household }\end{array}$ & $.062(.050)$ & $-.034(.050)$ & $.008(.050)$ & $-.024(.043)$ & $-.001(.039)$ \\
\hline Work: outside & $-.211 *(.094)$ & $.130(.093)$ & $-.232 *(.096)$ & $.108(.082)$ & $-.233 *(.075)$ \\
\hline $\begin{array}{l}\text { Work: from home as } \\
\text { before }\end{array}$ & $.064(.169)$ & $-.187(.170)$ & $.042(.171)$ & $-.221(.146)$ & $.240(.134)$ \\
\hline Work: no work & $-.218(.158)$ & $.224(.160)$ & $.022(.161)$ & $.111(.137)$ & $.021(.125)$ \\
\hline $\begin{array}{l}\text { Working hours: full } \\
\text { time }\end{array}$ & $-.138(.172)$ & $.238(.173)$ & $-.086(.175)$ & $-.006(.148)$ & $.166(.136)$ \\
\hline $\begin{array}{l}\text { Working hours: part } \\
\text { time }\end{array}$ & $-.138(.165)$ & $.140(.167)$ & $.012(.168)$ & $-.167(.142)$ & $.224(.131)$ \\
\hline School type ${ }^{c}$ & $.015(.116)$ & $-.154(.116)$ & $.145(.117)$ & $.056(.100)$ & $.035(.092)$ \\
\hline Relationship status ${ }^{\mathrm{d}}$ & $-.008(.104)$ & $.143(.104)$ & $-.220 *(.104)$ & $.116(.089)$ & $-.216^{*}(.082)$ \\
\hline
\end{tabular}


DISTANCE LEARNING AND AFFECTIVE WELL-BEING IN TIMES OF COVID-19

\begin{tabular}{llllll}
\hline & \multicolumn{5}{c}{$\begin{array}{c}\text { Random effects } \\
\text { (standard deviations) }\end{array}$} \\
\cline { 2 - 6 } Intercept & .850 & .834 & .854 & .714 & .667 \\
Distance learning & .449 & .269 & .254 & .296 & .216 \\
Stressor & .515 & .287 & .344 & .335 & .283 \\
Residual & .995 & .860 & .811 & .785 & .733 \\
\hline
\end{tabular}

Note. Table depicts unstandardized coefficients (standard errors for fixed effects in parentheses). Number of observations $=7,269-7,291$;

Number of participants $=538-540$.

${ }^{\mathrm{a}} 0=$ during the weekend or Easter vacation, $1=\operatorname{school~day;~}{ }^{\mathrm{b}} 0=$ female, $1=$ male; ${ }^{\mathrm{c}} 0=$ secondary school, academic tier (“Gymnasium”), $1=$ other school type; ${ }^{\mathrm{d}} 0=$ not married or in permanent relationship, $1=$ married or in permanent relationship.

$* p<.05$. 
DISTANCE LEARNING AND AFFECTIVE WELL-BEING IN TIMES OF COVID-19

\section{Table 3}

Results of Multilevel Models With Parental Involvement as Predictor

\begin{tabular}{|c|c|c|c|c|c|}
\hline & $\begin{array}{l}\text { Negative } \\
\text { Interactions } \\
\text { Model 1b }\end{array}$ & $\begin{array}{l}\text { Parental Positive } \\
\text { Affect } \\
\text { Model 2b }\end{array}$ & $\begin{array}{l}\text { Parental Negative } \\
\text { Affect } \\
\text { Model 3b }\end{array}$ & $\begin{array}{l}\text { Child Positive Affect } \\
\text { Model 4b }\end{array}$ & $\begin{array}{l}\text { Child Negative } \\
\text { Affect } \\
\text { Model 5b }\end{array}$ \\
\hline & & & Fixed Effects & 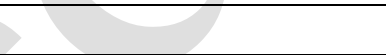 & \\
\hline Intercept & $2.996 *(.247)$ & $4.339 *(.250)$ & $2.739 *(.254)$ & $5.072 *(.209)$ & $2.285 *(.191)$ \\
\hline \multicolumn{6}{|l|}{ Within-person effects } \\
\hline Parental Involvement & $.207 *(.018)$ & $-.068 *(.014)$ & $.052 *(.014)$ & $-.133 *(.014)$ & $.093 *(.013)$ \\
\hline Stressor & $.655 *(.057)$ & $-.653 *(.043)$ & $.686 *(.044)$ & $-.376 *(.042)$ & $.360 *(.041)$ \\
\hline \multicolumn{6}{|l|}{ Between-person effects } \\
\hline Parental Involvement & $.300 *(.030)$ & $-.091 *(.030)$ & $.087 *(.030)$ & $-.170 *(.025)$ & $.124 *(.023)$ \\
\hline Stressor & $1.057 *(.147)$ & $-1.035^{*}(.147)$ & $1.561 *(.150)$ & $-.601 *(.123)$ & $.878^{*}(.113)$ \\
\hline \multicolumn{6}{|l|}{ Covariates } \\
\hline School day ${ }^{\mathrm{a}}$ & $.190 *(.044)$ & $-.156 *(.038)$ & $.036(.038)$ & $-.142 *(.035)$ & $.031(.033)$ \\
\hline Child age & $-.078 *(.021)$ & $-.016(.021)$ & $.012(.021)$ & $-.053 *(.017)$ & $-.020(.016)$ \\
\hline Child gender ${ }^{b}$ & $.180 *(.084)$ & $-.095(.085)$ & $.011(.086)$ & $-.133(.071)$ & $-.076(.065)$ \\
\hline $\begin{array}{l}\text { Number of children in } \\
\text { household }\end{array}$ & $.012(.054)$ & $-.052(.055)$ & $.024(.056)$ & $-.004(.046)$ & $-.015(.042)$ \\
\hline Work: outside & $-.343 *(.102)$ & $.167(.104)$ & $-.266 *(.106)$ & $.183 *(.087)$ & $-.230 *(.079)$ \\
\hline $\begin{array}{l}\text { Work: from home as } \\
\text { before }\end{array}$ & $-.284(.188)$ & $-.067(.190)$ & $-.150(.193)$ & $.089(.159)$ & $.087(.145)$ \\
\hline Work: no work & $-.344 *(.170)$ & $.336(.172)$ & $-.062(.175)$ & $.199(.144)$ & $-.107(.131)$ \\
\hline $\begin{array}{l}\text { Working hours: full } \\
\text { time }\end{array}$ & $-.267(.186)$ & $.349(.188)$ & $-.215(.191)$ & $.087(.157)$ & $.033(.143)$ \\
\hline $\begin{array}{l}\text { Working hours: part } \\
\text { time }\end{array}$ & $-.333(.178)$ & $.261(.180)$ & $-.102(.183)$ & $-.028(.151)$ & $.131(.137)$ \\
\hline School type ${ }^{c}$ & $-.135(.126)$ & $-.161(.128)$ & $.146(.130)$ & $.024(.107)$ & $-.011(.097)$ \\
\hline Relationship status ${ }^{\mathrm{d}}$ & $-.074(.114)$ & $.185(.116)$ & $-.279 *(.117)$ & $.032(.097)$ & $-.190 *(.088)$ \\
\hline
\end{tabular}


DISTANCE LEARNING AND AFFECTIVE WELL-BEING IN TIMES OF COVID-19

\begin{tabular}{llllll}
\hline & \multicolumn{5}{c}{$\begin{array}{c}\text { Random effects } \\
\text { (standard deviations) }\end{array}$} \\
\cline { 2 - 6 } Intercept & .803 & .839 & .861 & .690 & .638 \\
Parental Involvement & .161 & .089 & .090 & .118 & .121 \\
Stressor & .541 & .248 & .305 & .366 & .362 \\
Residual & .984 & .834 & .820 & .751 & .716 \\
\hline Nosi Tale
\end{tabular}

Note. Table depicts unstandardized coefficients (standard errors for fixed effects in parentheses). Number of observations $=2,824-2,828$;

Number of participants $=513-514$.

${ }^{\mathrm{a}} 0=$ during the weekend or Easter vacation, $1=\operatorname{school}$ day; ${ }^{\mathrm{b}} 0=$ female, $1=$ male; ${ }^{\mathrm{c}} 0=$ secondary school, academic tier (“Gymnasium”), $1=$ other school type; ${ }^{\mathrm{d}} 0=$ not married or in permanent relationship, $1=$ married or in permanent relationship.

$* p<.05$. 


\section{Table 4}

Results of the Multilevel Mediation Model

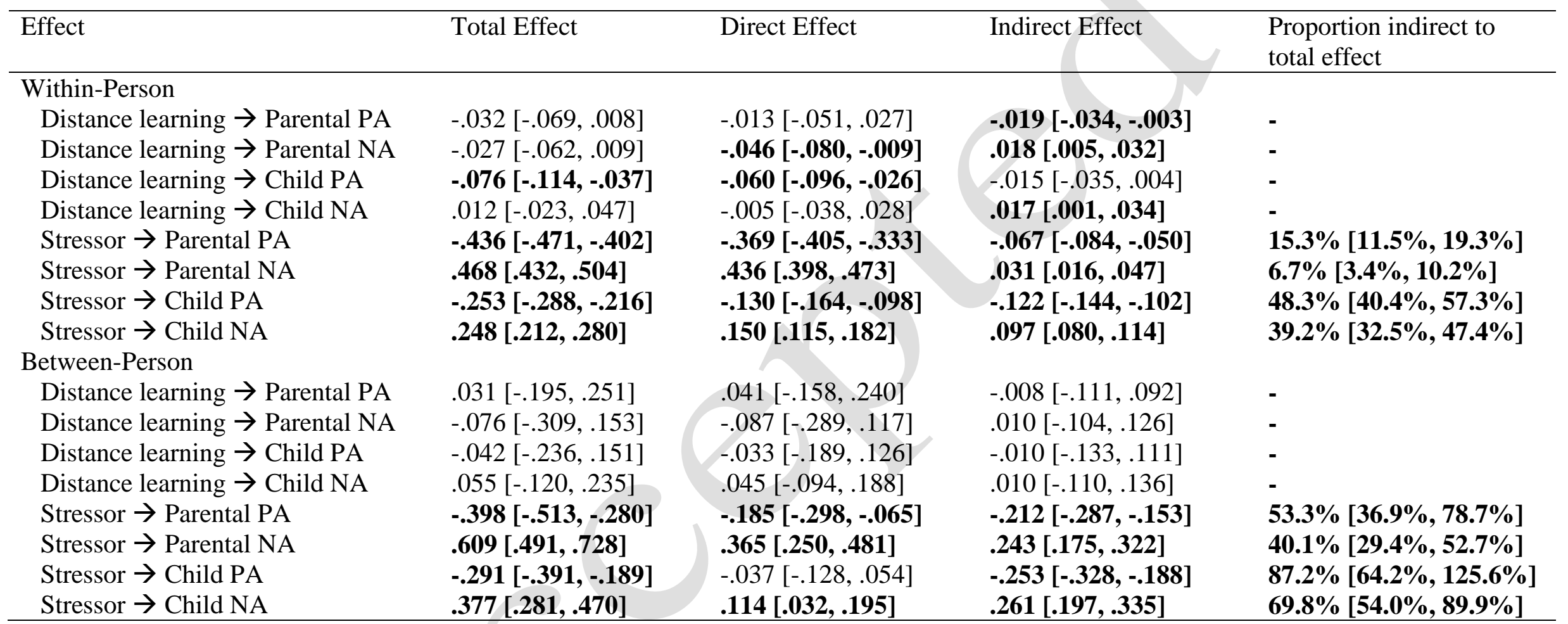

Note. $\mathrm{PA}=$ positive affect; $\mathrm{NA}=$ negative affect. Credible intervals of the effects are presented in parentheses. Parameters whose $95 \%$ credible

interval does not include zero are highlighted in bold. The proportion of indirect to total effect was computed of each draw of the MCMC

estimation. It is only reported for those effects in which total and indirect effects were statistically meaningful. 


\section{Figure 1}

Multilevel Mediation Model

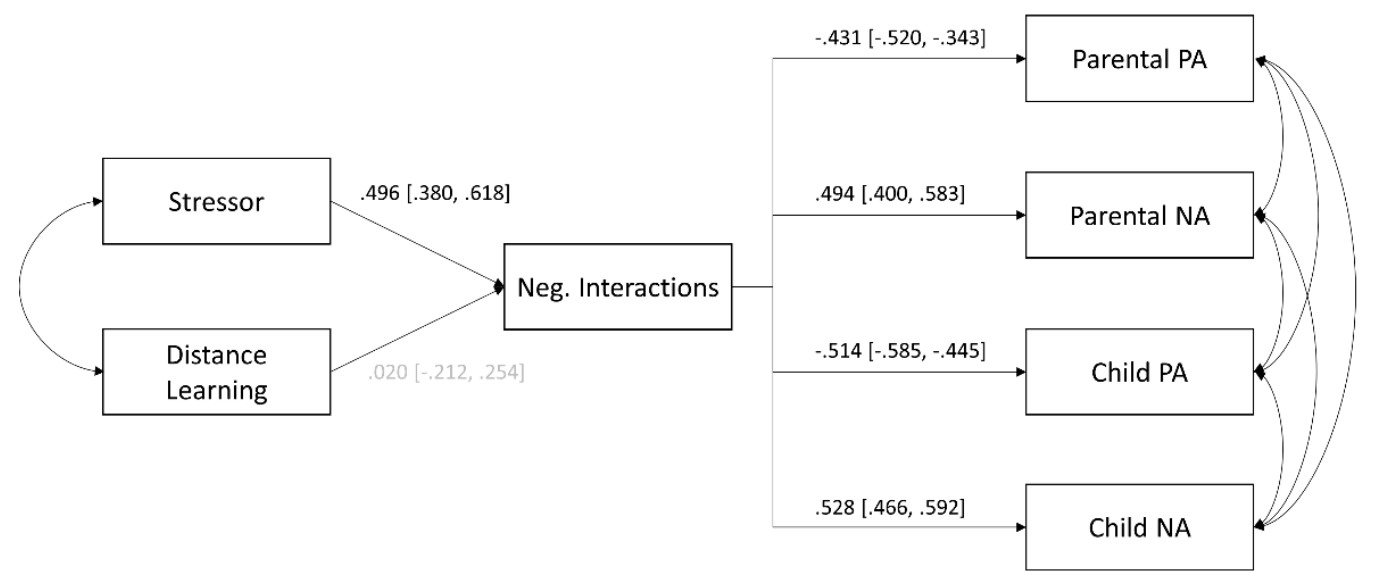

Between

Within

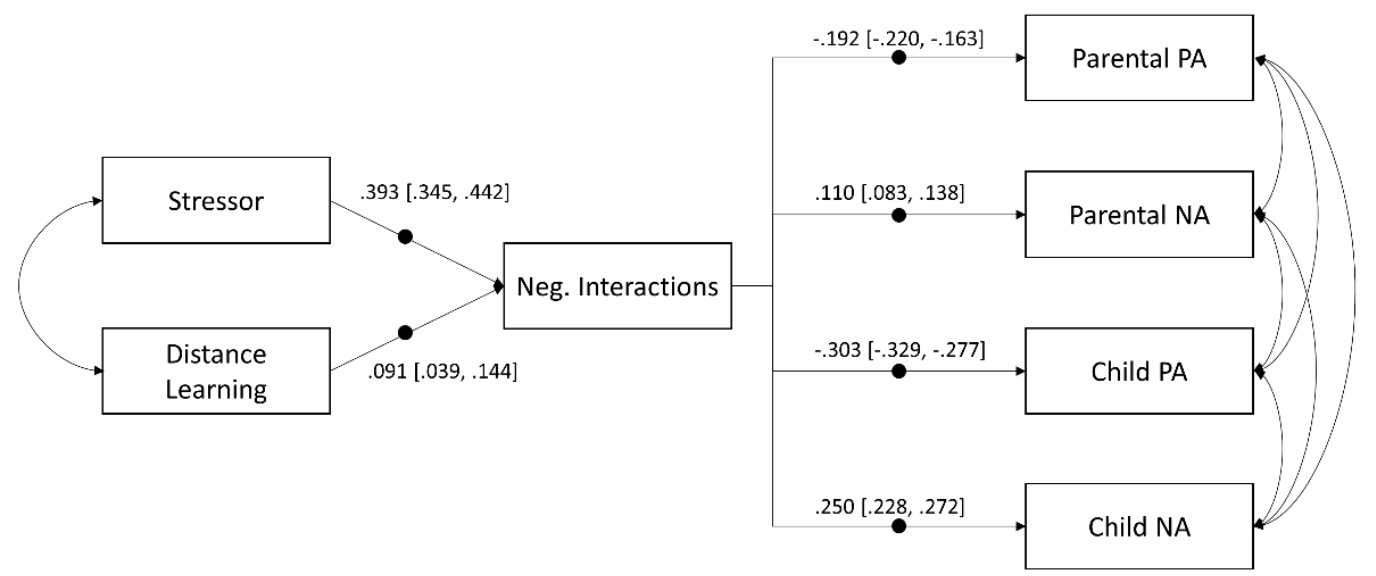

Note. Schematic representation of the multilevel mediation model depicting unstandardized regression coefficients and their $95 \%$ credible interval. Random effects were estimated for the six depicted regression coefficients (see black dots). Direct effects of stress and distance 
learning on the four affective well-being measures (as well as random effects of these direct effects) were estimated but are not depicted for better legibility (see Table 4 for direct effects). Covariates were included but are not depicted here; see Mplus output on the OSF repository for full model results including the estimated (residual) covariance. Neg. Interactions $=$ Negative parent-child interactions; $\mathrm{PA}=$ positive affect $; \mathrm{NA}=$ negative affect . 
DISTANCE LEARNING AND AFFECTIVE WELL-BEING IN TIMES OF COVID-19

\section{Figure 2}

Heterogeneity of Within-Person Effects of Distance Learning.

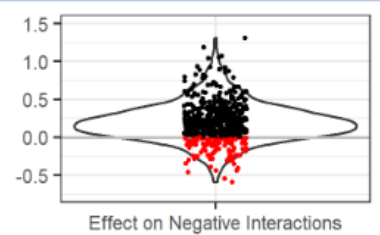

$r=-0.304$

$r=0.315$

$r=-0.544$

$r=-0.359$

$r=0.454$

$r=-0.243$
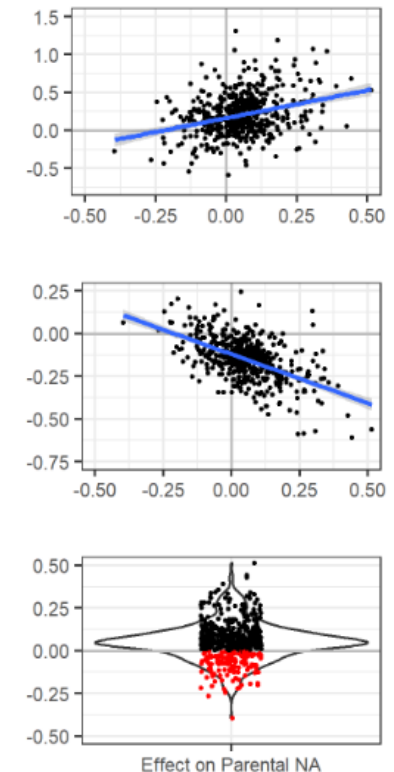

$r=-0.307$

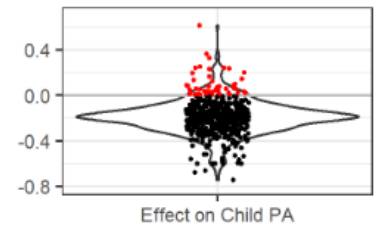

$r=-0.526$
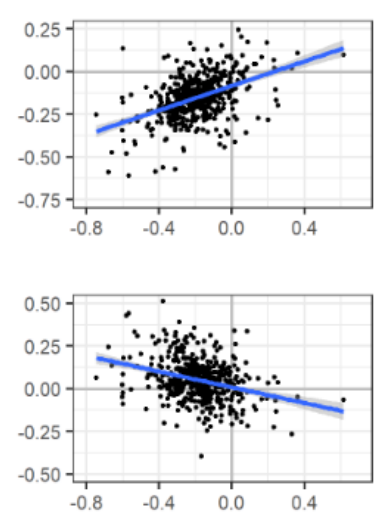
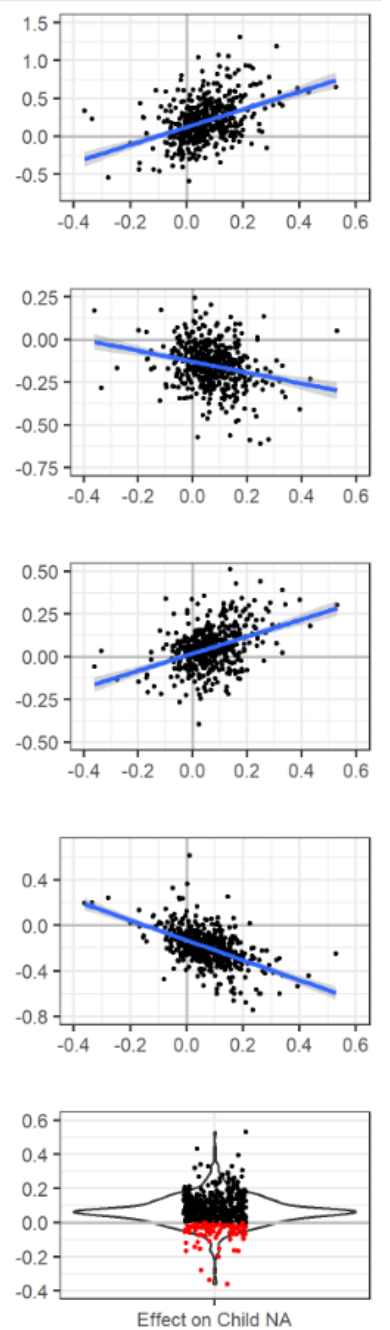
DISTANCE LEARNING AND AFFECTIVE WELL-BEING IN TIMES OF COVID-19

Note. Figure depicts the distribution of five regression coefficients involving daily distance learning (diagonal), bivariate scatterplots among these regression coefficients (upper diagonal) and their intercorrelations (lower diagonal). Each data point represents one participant. In the plots in the diagonal, participants whose estimated regression coefficient has the same sign as the fixed effect (i.e., the average regression coefficient in the sample) are depicted in black. Participants whose estimated regression coefficient has the opposite sign as the fixed effect are depicted in red. 


\section{Figure 3}

Estimated Quadratic Between-Person Effect of Distance Learning on Negative Parent-Child Interactions

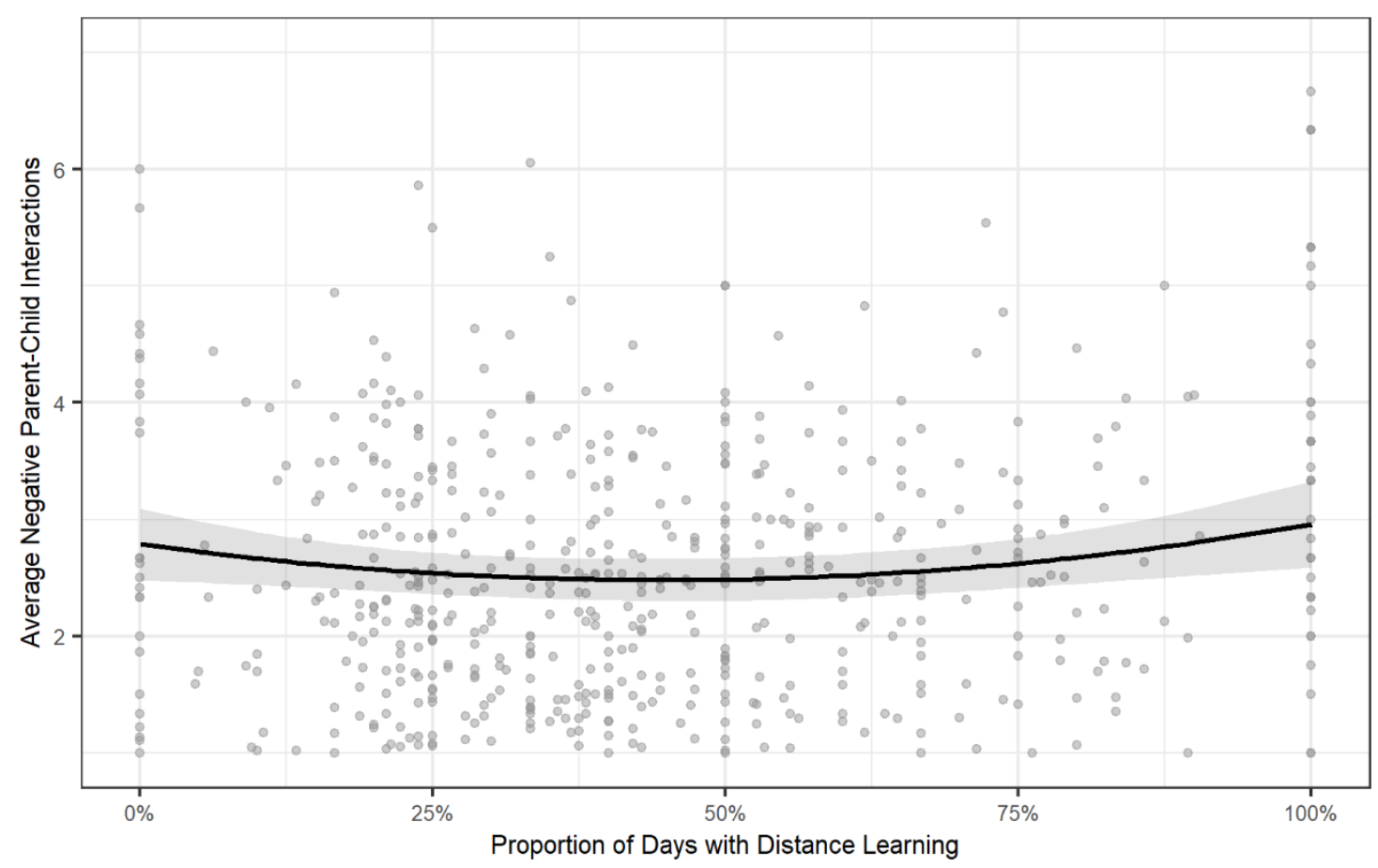

Note. Figure depicts estimated quadratic association between the proportion of days with distance learning and average negative parent-child interaction reported across the three weeks. Grey dots represent individual participants. 


\section{References}

Ager, A., Stark, L., Akesson, B., \& Boothby, N. (2010). Defining best practice in care and protection of children in crisis-affected settings: A Delphi study. Child Development, 81(4), 1271-1286. https://doi.org/10.1111/j.1467-8624.2010.01467.x.

Almeida, D. M., Wethington, E., \& Kessler, R. C. (2002). The Daily Inventory of Stressful Experiences: An interview-based approach for measuring daily stressors. Assessment, 9(1), 41-55. https://doi.org/10.1177/1073191102009001006

Asparouhov, T., \& Muthén, B. (2019). Latent variable centering of predictors and mediators in multilevel and time-series models. Structural Equation Modeling: A Multidisciplinary Journal, 26(1), 119-142. https://doi.org/10.1080/10705511.2018.1511375

Bansak, C., \& Starr, M. (2021). Covid-19 shocks to education supply: How 200,000 U.S. households dealt with the sudden shift to distance learning. Reviews of Economics of the Household, 19, 6390. https://doi.org/10.1007/s11150-020-09540-9

Barger, M. M., Kim, E. M., Kuncel, N. R., \& Pomerantz, E. M. (2019). The relation between parents' involvement in children's schooling and children's adjustment: A meta-analysis. Psychological Bulletin, 145(9), 855-890. https://doi.org/10.1037/bul0000201

Betancourt, T. S., Borisova, I. I., Williams, T. P., Brennan, R. T., Whitfield, T. H., La Soudiere, M. de, . . Gilman, S. E. (2010). Sierra Leone's former child soldiers: A followup study of psychosocial adjustment and community reintegration. Child Development, 81(4), 1077-1095. https://doi.org/10.1111/j.1467-8624.2010.01455.x

Blume, F., Schmidt, A., Kramer, A. C., Schmiedek, F., \& Neubauer, A. B. (2021). Homeschooling during the SARS-CoV-2 pandemic: The role of students' trait selfregulation and task attributes of daily learning tasks for students' daily self-regulation. Zeitschrift für Erziehungswissenschaft, 24(2), 367-391. https://doi.org/10.1007/s11618-021-01011-w 
Boutelle, K., Eisenberg, M. E., Gregory, M. L., \& Neumark-Sztainer, D. (2009). The reciprocal relationship between parent-child connectedness and adolescent emotional functioning over 5 years. Journal of Psychosomatic Research, 66(4), 309-316. https://doi.org/10.1016/j.jpsychores.2008.10.019

Branje, S. J. T., Hale, W. W., Frijns, T., \& Meeus, W. H. J. (2010). Longitudinal associations between perceived parent-child relationship quality and depressive symptoms in adolescence. Journal of Abnormal Child Psychology, 38(6), 751-763. https://doi.org/10.1007/s10802-010-9401-6

Bronfenbrenner, U. (1986). Ecology of the family as a context for human development: Research perspectives. Developmental Psychology, 22(6), 723-742. https://doi.org/10.1037/0012-1649.22.6.723

Brose, A., Schmiedek, F., Lövdén, M. \& Lindenberger, U. (2011). Normal aging dampens the link between intrusive thoughts and negative affect in reaction to daily stressors. Psychology and Aging, 26, 488-502. https://doi.org/10.1037/a0022287

Brown, S. M., Doom, J., Watamura, S., Lechuga-Pena, S., \& Koppels, T. (2020, June 29). Stress and parenting during the global COVID-19 pandemic. Child Abuse \& Neglect, 110(2), 104699. https://doi.org/10.1016/j.chiabu.2020.104699.

Campbell, A. M. (2020). An increasing risk of family violence during the Covid-19 pandemic: Strengthening community collaborations to save lives. Forensic Science International: Reports, 2, 100089. https://doi.org/10.1016/j.fsir.2020.100089

Chemtob, C. M., Nomura, Y., Rajendran, K., Yehuda, R., Schwartz, D., \& Abramovitz, R. (2010). Impact of maternal posttraumatic stress disorder and depression following exposure to the September 11 attacks on preschool children's behavior. Child Development, 81(4), 1129-1141. https://doi.org/10.1111/j.1467-8624.2010.01458.x. 
Chen, C. Y. C., Byrne, E., \& Vélez, T. (2021). Impact of the 2020 pandemic of COVID-19 on families with school-aged children in the United States: Roles of income level and race. Journal of Family Issues, Advance Online Publication. https://doi.org/10.1177/0192513X21994153.

Chung, G., Lanier, P., \& Ju, P. W. Y. (2020). Mediating effects of parental stress on harsh parenting and parent-child relationship during coronavirus (COVID-19) pandemic in Singapore. Journal of Family Violence. Advance Online Publication. https://doi.org/10.1007/s10896-020-00200-1

Chung, G. H., Flook, L., \& Fuligni, A. J. (2009). Daily family conflict and emotional distress among adolescents from Latin American, Asian, and European backgrounds. Developmental Psychology, 45(5), 1406-1415. https://doi.org/10.1037/a0014163

Clark, K. E., \& Ladd, G. W. (2000). Connectedness and autonomy support in parent-child relationships: Links to children's socioemotional orientation and peer relationships. Developmental Psychology, 36(4), 485-498.

Collins, W. A., \& Steinberg, L. (2006). Adolescent development in interpersonal context. In W. Damon, R. Lerner, \& N. Eisenberg (Eds.), The handbook of child psychology, vol 3: Social, emotional and personality development (6th ed., pp. 1003-1067). Hoboken, NJ: John Wiley \& Sons.

Craig, L. \& Churchill, B. (2020). Dual-earner parent couples' work and care during COVID19. Gender, Work \& Organization, 1-14. https://doi.org/10.1111/gwao.12497

Crespo, C., Santos, S., Canavarro, M. C., Kielpikowski, M., Pryor, J., \& Féres-Carneiro, T. (2013). Family routines and rituals in the context of chronic conditions: a review. International Journal of Psychology, 48(5), 729-746. https://doi.org/10.1080/00207594.2013.806811 
Daly, M., Sutin, A., \& Robinson, E. (2020). Longitudinal changes in mental health and the COVID-19 pandemic: Evidence from the UK Household Longitudinal Study. Psychological Medicine, Advance Online Publication. https://doi.org/ $10.1017 / \mathrm{S} 0033291720004432$

Davis, C. R., Grooms, J., Ortega, A., Rubalcaba, J. A.-A., \& Vargas, E. (2021). Distance learning and parental mental health during COVID-19. Educational Researcher, 50(1), 61-64. https://doi.org/10.3102/0013189X20978806

Eltanamly, H., Leijten, P., Jak, S., \& Overbeek, G. (2019). Parenting in times of war: A metaanalysis and qualitative synthesis of war exposure, parenting, and child adjustment. Trauma, Violence \& Abuse, 1-14. https://doi.org/10.1177/1524838019833001

Estrada, P., Arsenio, W. F., Hess, R. D., \& Holloway, S. D. (1987). Affective quality of the mother-child relationship: Longitudinal consequences for children's school-relevant cognitive functioning. Developmental Psychology, 23(2), 210-215. https://doi.org/10.1037/0012-1649.23.2.210

Fan, X., \& Chen, M. (2001). Parental involvement and students' academic achievement: A meta-analysis. Educational Psychology Review, 13(1), 1-22. https://doi.org/10.1023/A:1009048817385

Gambin, M., Woźniak-Prus, M., Sekowski, M., Cudo, A., Pisula, E., Kiepura, E., ...., Kmita, G. (2020, July 30). Factors related to positive experiences in parent-child relationship during the COVID-19 lockdown: The role of empathy, emotion regulation, parenting selfefficacy and social support. https://doi.org/10.31234/osf.io/yhtqa

Gao, M. M., \& Cummings, E. M. (2019). Understanding parent-child relationship as a developmental process: Fluctuations across days and changes over years. Developmental Psychology, 55(5), 1046-1058. https://doi.org/10.1037/dev0000680 
Geldhof, G. J., Preacher, K. J., \& Zyphur, M. J. (2014). Reliability estimation in a multilevel confirmatory factor analysis framework. Psychological Methods, 19(1), 72-91. https://doi.org/10.1037/a0032138

Guo, J., De Carli, P., Lodder, P., Bakermans-Kranenburg, M. J., \& Riem, M. (2021). Maternal mental health during the COVID-19 lockdown in China, Italy, and the Netherlands: A cross-validation study. Psychological Medicine, Advance Online Publication. https://doi.org/10.1017/S0033291720005504

Harper, F. K., Rosenberg, J. M., Comperry, S.; Howell, K., Womble, S. (2021).

\#Mathathome during the COVID-19 pandemic: Exploring and reimagining resources and social supports for parents. Education Sciences, 11(60), 1-24.

https://doi.org/10.3390/educsci11020060

Harrist, A. W., Henry, C. S., Liu, C., \& Morris, A. S. (2019). Family resilience: The power of rituals and routines in family adaptive systems. In B. H. Fiese, M. Celano, K. DeaterDeckard, E. N. Jouriles, \& M. A. Whisman (Eds.), APA handbook of contemporary family psychology: Foundations, methods, and contemporary issues across the lifespan (Vol. 1) (pp. 223-239). Washington: American Psychological Association. https://doi.org/10.1037/0000099-013

Hiraoka, D., \& Tomoda, A. (2020). The relationship between parenting stress and school closures due to the COVID-19 pandemic. Psychiatry and Clinical Neurosciences. Advance Online Publication. https://doi.org/10.1111/pcn.13088

Huang, C.-Y., Hsieh, Y.-P., Shen, A. C.-T., Wei, H.-S., Feng, J.-Y., Hwa, H.-L., \& Feng, J. Y. (2019). Relationships between parent-reported parenting, child-perceived parenting, and children's mental health in Taiwanese children. International Journal of Environmental Research and Public Health, 16(6), 1049. https://doi.org/10.3390/ijerph16061049 
Huber, S. G., Günther, P. S., Schneider, N., Helm, C., Schwander, M., Schneider, J., \& Pruitt, J. (2020). COVID-19 und aktuelle Herausforderungen in Schule und Bildung: Erste Befunde des Schul-Barometers in Deutschland, Österreich und der Schweiz [COVID-19 and current challenges in school and education: First findings of the School Barometer in Germany, Austria and Switzerland]: Waxmann Verlag GmbH.

Huebener, M., Waights, S., Spieß, C. K., Siegel, N. A., Wagner, G. G. (2020). Parental wellbeing in times of Covid-19 in Germany. SOEPpapers on Multidisciplinary Panel Data Research, No. 1099, Deutsches Institut für Wirtschaftsforschung (DIW), Berlin. Retrieved from http://hdl.handle.net/10419/224088

Janssen, L. H. C., Kullberg, M-L. J., Verkuil, B., van Zwieten, N., Wever, M. C. M, ..\& Elzinga, B. M. (2020). Does the COVID-19 pandemic impact parents' and adolescents' well-being? An EMA study on daily affect and parenting. PLOS ONE, 15(10), e0240962. https://doi.org/10.1371/journal.pone.0240962

Jeynes, W. H. (2005). A meta-analysis of the relation of parental involvement to urban elementary school student academic achievement. Urban Education, 40(3), 237-269. https://doi.org/10.1177/0042085905274540

Juth, V., Silver, R. C., Seyle, D. C., Widyatmoko, C. S., \& Tan, E. T. (2015). Post-disaster mental health among parent-child dyads after a major earthquake in Indonesia. Journal of Abnormal Child Psychology, 43(7), 1309-1318. https://doi.org/10.1007/s10802-015-00098

Katz, I., Buzukashvili, T., \& Feingold, L. (2012). Homework stress: Construct validation of a measure. The Journal of Experimental Education, 80(4), 405-421. https://doi.org/10.1080/00220973.2011.610389 
Kenny, D. A., Korchmaros, J. D., \& Bolger, N. (2003). Lower level mediation in multilevel models. Psychological Methods, 8(2), 115-128. https://doi.org/10.1037/1082989X.8.2.115

Kerns, C. E., Elkins, R. M., Carpenter, A. L., Chou, T., Green, J. G., \& Comer, J. S. (2014). Caregiver distress, shared traumatic exposure, and child adjustment among area youth following the 2013 Boston marathon bombing. Journal of Affective Disorders, 167, 50-55. https://doi.org/10.1016/j.jad.2014.05.040

Lades, L. K., Laffan, K., Daly, M., \& Delaney, L. (2020). Daily emotional well-being during the COVID-19 pandemic. British Journal of Health Psychology, 25, 902-911. https://doi.org/10.1111/bjhp.12450

Laursen, B., \& Collins, W. A. (2009). Parent-child relationships during adolescence. In R. M. Lerner \& L. Steinberg (Eds.), Handbook of Adolescent Psychology. Hoboken, NJ, USA: John Wiley \& Sons, Inc. https://doi.org/10.1002/9780470479193.adlpsy002002

Liu, S., Kuppens, P., \& Bringmann, L. (2021). On the use of empirical Bayes estimates as measures of individual traits. Assessment, 28(3), 845-857. https://doi.org/10.1177/1073191119885019

Magson, N. R., Freeman, J. Y. A., Rapee, R. M., Richardson, C. E., \& Oar, E. L. (2021). Risk and protective factors for prospective changes in adolescent mental health during the COVID-19 pandemic. Journal of Youth and Adolescence, 50, 44-57.

https://doi.org/10.1007/s10964-020-01332-9

Mastrotheodoros, S., Van Lissa, C. J., Van der Graaff, J., Deković, M., Meeus, W. H. J., \& Branje, S. J. T. (2020). Day-to-day spillover and long-term transmission of interparental conflict to adolescent-mother conflict: The role of mood. Journal of Family Psychology, 34(8), 893-904. https://doi.org/10.1037/fam0000649 
Mastrotheodoros, S., Van der Graaff, J., Deković, M., Meeus, W. H. J., \& Branje, S. (2020). Parentadolescent conflict across adolescence: Trajectories of informant discrepancies and associations with personality types. Journal of Youth and Adolescence, 49, 119-135. https://doi.org/10.1007/s10964-019-01054-7

McCrory Calarco, J., Meanwell, E., Anderson, E., Knopf, A. (2020, October 4). “Let’s not pretend it's fun": How disruptions to families' school and childcare arrangements impact mothers' well-being. https://doi.org/10.31235/osf.io/jyvk4

Meunier, J. C., Bisceglia, R., \& Jenkins, J. M. (2012). Differential parenting and children's behavioral problems: Curvilinear associations and mother-father combined effects. Developmental Psychology, 48(4), 987-1002. https://doi.org/10.1037/a0026321

Miguel, F. F., Prudente, M. S., Aguja, S. E. (2021). Teachers' initiatives and perceived parental involvement practices among Filipino junior high school students. Paper presented at the 12th International Conference on E-Education, E-Business, EManagement, and E-Learning (IC4E) 2021 in Tokyo, Japan. https://doi.org/10.1145/3450148.3450173

Moroni, S., Dumont, H., Trautwein, U., Niggli, A., \& Baeriswyl, F. (2015). The need to distinguish between quantity and quality in research on parental involvement: The example of parental help with homework. The Journal of Educational Research, 108(5), 417-431. https://doi.org/10.1080/00220671.2014.901283

Neubauer, A. B., Schmidt, A., Kramer, A. C., \& Schmiedek, F. (2021). A little autonomy support goes a long way: Daily autonomy-supportive parenting, child well-being, parental need fulfillment, and change in child, family, and parent adjustment across the adaptation to the COVID-19 pandemic. Child Development. Advance Online Publication. https://doi.org/10.1111/cdev.13515 
Neubauer, A. B., Smyth, J. M., Sliwinski, M. J. (2019). Age differences in proactive coping with minor hassles in daily life. The Journals of Gerontology: Series B, 74(1), 7-16. https://doi.org/10.1093/geronb/gby061

Neubauer, A. B., Voelkle, M. C., Voss, A., \& Mertens, U. K.(2020). Estimating reliability of within-person couplings in a multilevel framework. Journal of Personality Assessment, 102(1), 10-21. https://doi.org/10.1080/00223891.2018.1521418

Piazza, J. R., Charles, S. T., Sliwinski, M. J., Mogle, J., Almeida, D. M. (2013). Affective reactivity to daily stressors and long-term risk of reporting a chronic physical health condition. Annals of Behavioral Medicine, 45(1), 110-120. https://doi.org/10.1007/s12160$\underline{012-9423-0}$

Pinheiro, J., Bates, D., DebRoy, S., Sakar, D., \& R Core Team (2019). nlme: Linear and nonlinear mixed effects models. Retrieved from https://cran.rproject.org/web/packages/nlme/citation.html

Pomerantz, E. M., Moorman, E. A., \& Litwack, S. D. (2007). The how, whom, and why of parents' involvement in children's academic lives: More is not always better. Review of Educational Research, 77(3), 373-410. https://doi.org/10.3102/003465430305567

Pomerantz, E. M., Wang, Q., \& Ng, F. F.-Y. (2005). Mothers' affect in the homework context: The importance of staying positive. Developmental Psychology, 41(2), 414-427. https://doi.org/10.1037/0012-1649.41.2.414

Preacher, K. J., Zyphur, M. J., \& Zhang, Z. (2010). A general multilevel SEM framework for assessing multilevel mediation. Psychological Methods, 15(3), 209-233. https://doi.org/10.1037/a0020141

Prime, H., Wade, M., \& Browne, D. T. (2020). Risk and resilience in family well-being during the COVID-19 pandemic. The American Psychologist, 75(5), 631-643. https://doi.org/10.1037/amp0000660 
Raudino, A., Fergusson, D. M., \& Horwood, L. J. (2013). The quality of parent/child relationships in adolescence is associated with poor adult psychosocial adjustment. Journal of Adolescence, 36(2), 331-340.

https://doi.org/10.1016/j.adolescence.2012.12.002

Romero, E., López-Romero, L., Domínguez-Álvarez, B., Villar, P., \& Gómez-Fraguela, J. A. (2020). Testing the effects of COVID-19 confinement in Spanish children: The role of parents' distress, emotional problems and specific parenting. International Journal of Environmental Research and Public Health, 17(19), 6975. https://doi.org/10.3390/ijerph17196975

Schermerhorn, A. C., Chow, S.-M., \& Cummings, E. M. (2010). Developmental family processes and interparental conflict: Patterns of microlevel influences. Developmental Psychology, 46(4), 869-885. https://doi.org/10.1037/a0019662

Schmidt, A., Brose, A., Kramer, A. C., Schmiedek, F., \& Neubauer, A. B. (2020). Homeschooling, daily stressors, negative parent-child interactions, and affective wellbeing in times of the COVID-19 pandemic. Open Science Framework. https://osf.io/ugkj2/

Scott, S. B., Ram, N., Smyth, J. M., Almeida, D. M., \& Sliwinski, M. J. (2017). Age differences in negative emotional responses to daily stressors depend on time since event. Developmental Psychology, 53(1), 177-190. https://doi.org/10.1037/dev0000257

Sentse, M., Veenstra, R., Lindenberg, S., Verhulst, F. C., \& Ormel, J. (2009). Buffers and risks in temperament and family for early adolescent psychopathology: Generic, conditional, or domain-specific effects? The trails study. Developmental Psychology, 45(2), 419-430. https://doi.org/10.1037/a0014072

The World Bank (2021). Population, Total. Retrieved from https://data.worldbank.org/indicator/SP.POP.TOTL on April 6th, 2021. 
Thorell, L. B., Skoglund, C., de la Peña, A. G., Baeyens, D., Fuermaier, A. B. M., ..,, Christiansen, H. (2021). Parental experiences of homeschooling during the COVID-19 pandemic: differences between seven European countries and between children with and without mental health conditions. European Child \& Adolescent Psychiatry. Advance Online Publication. https://doi.org/10.1007/s00787-020-01706-1

UNESCO (2020). COVID-19 impact on education. Retrieved from https://en.unesco.org/covid19/educationresponse

Wang, L. P., \& Maxwell, S. E. (2015). On disaggregating between-person and within-person effects with longitudinal data using multilevel models. Psychological Methods, 20(1), 6383. https://doi.org/10.1037/met0000030

Westrupp, E., Stokes, M. A., Fuller-Tyszkiewicz, M., Berkowitz, T. S., Capic, T., Khor, S., Greenwood, C. J., Mikocka-Walus, A., Sciberras, E., Youssef, G. J., Olsson, C. A., Hutchinson, D., Cummins, R. (2020, October 27). Subjective wellbeing in parents during the COVID-19 pandemic in Australia. https://doi.org/10.31234/osf.io/8nvm3

Whittle, S., Bray, K., Chu Lin, S., Schwartz, O. (2020, August 5). Parenting and child and adolescent mental health during the COVID-19 pandemic.

https://doi.org/10.31234/osf.io/ag2r7

Wildemann, A. \& Hosenfeld, I. (2020). Bundesweite Elternbefragung zum Homeschooling während der Covid 19-Pandemie. Erkenntnisse zur Umsetzung des Homeschoolings in Deutschland [Nationwide parents survey regarding homeschooling during the Covid 19 pandemic. Insights on the implementation of homeschooling in Germany]. Retrieved from https://homeschoolingstudie2020.zepf.eu 